\title{
Climatic Cycles and Gradients of the El Niño Core Region in North Peru
}

\author{
Rütger Rollenbeck, ${ }^{1}$ Fabian Bayer, ${ }^{1}$ Jannes Müinchow, ${ }^{2}$ Michael Richter, ${ }^{2}$ \\ Rodolfo Rodriguez, ${ }^{3}$ and Nestor Atarama ${ }^{3}$ \\ ${ }^{1}$ Laboratory for Climatology and Remote Sensing (LCRS), Faculty of Geography, University of Marburg, 35032 Marburg, Germany \\ ${ }^{2}$ Institute of Geography, University of Erlangen-Nuremberg, 91052 Erlangen, Germany \\ ${ }^{3}$ Facultad de Ingeneria, Universidad de Piura, Piura 20000, Peru \\ Correspondence should be addressed to Rütger Rollenbeck; rollenbeck@lcrs.de
}

Received 30 January 2015; Revised 17 March 2015; Accepted 18 March 2015

Academic Editor: Luis Gimeno

Copyright (C) 2015 Rütger Rollenbeck et al. This is an open access article distributed under the Creative Commons Attribution License, which permits unrestricted use, distribution, and reproduction in any medium, provided the original work is properly cited.

Climatic processes in northern Peru are evaluated on surface observation independent of modelling studies. The region is characterized by regular oscillations, but episodic El Niño-events introduce strong disturbances. Conceptual models based on observations, remote sensing data, and output of regional climate models are compared with data from a new station network. The results show regular oscillations of all climate variables on the annual and daily time scale. The daily cycle is probably associated with thermotidal forcings, causing gravity waves to emanate from the Andes Cordillera. Main factors are the interaction of large scale pressure systems like the Southeast Pacific High and the intertropical convergence zone (ITCZ). Also, there are regional factors: an extended sea-breeze system, the barrier-effect of the Andes, additional energy input by elevated radiation absorption at the mountain slopes, local wind systems, and the variations of the sea surface temperature. At the coast, a low-level jet works as a thermodynamic energy sink, suppressing deep convection and supporting the aridity. Those patterns are found in most of the station data and the processes of this climate can generally be confirmed. The overturning of this stable system with the onset of El Niño-conditions is possibly caused by disruptions of the regional circulation.

\section{Introduction}

The climatic conditions of the Sechura Desert in northwestern Peru most of the time show a striking regularity. They are governed by the south-hemispheric tropical cycle with a wetter season during the passage of the ITCZ and solar equinoctium in March, while the rest of the year is almost completely dry and marked by a cooler season from June to November.

In this study we will analyse climate data from a recently installed network of nine stations, forming the Niño-5-Network (termed after its location along the $5^{\circ}$ parallel south; see Figure 1), which is managed by the Universidad de Piura. The purpose of this work is to characterize key features of the climate of the region between the coast and the Andes mountain chain along the fifth parallel south of the equator. At the same time, the concepts of the local climate dynamics shall be evaluated with regard to their impact on the behaviour of the main climate variables. Additionally, the surface energy balance shall be addressed to understand the causes of the exceptional aridity of our study area. The analyses are intentionally limited to observed and measured data independent of the currently more common modelling studies (e.g., Takahashi [1], Toniazzo et al. [2]).

Much research has gone into studying the special conditions during strong El Niño-events, especially those of 1983 and 1998 (e.g., Caviedes and Endlicher [3], Bendix [4], Bendix [5], Chen [6], Takahashi [7], and Lagos et al. [8]), but the normal conditions of this region prevailing most of the time have hardly been analysed. The conventional explanation for the extreme aridity found along the coastal strip of Peru is the influence of the Eastern Pacific High pressure cell together with forced subsidence of the tropical easterlies after crossing the mountain barrier of the Andes (Johnson [9]). 


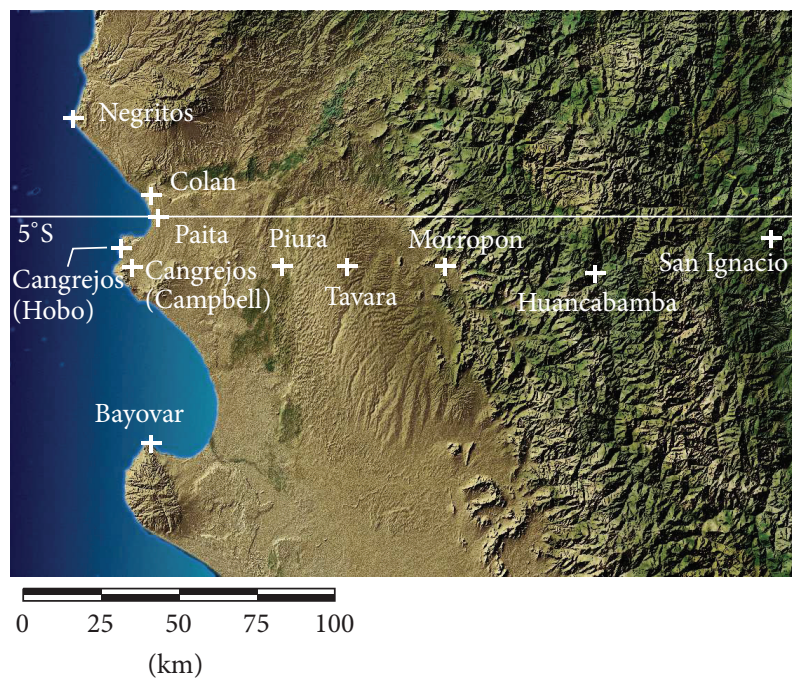

Figure 1: Overview map of the Piura Region and the climate stations used in this study.

However, this theory neither explains the sharp transition from extremely dry conditions in Peru to the more humid conditions in the coastal plains of Ecuador some $200 \mathrm{~km}$ to the north, nor does it supply a theoretical background to explain the seasonal variability or the drastic changes occurring with strong El Niño-conditions in Northern Peru.

Today it is well known (Bazo et al. [10], Bendix et al. [11]) that a main driver for this distinctive dryness of the Peruvian coast is the cold waters of the Humboldt current, generating strong subsidence and an associated inversion layer, which effectively suppresses moist convection, although there is plenty of atmospheric humidity (about $20-30 \mathrm{~g} / \mathrm{kg}$ ) at the surface level. Lettau [12-14] developed a conceptual model, explaining the atmospherical dynamics of Northern Peru. Although this concept is some decades old, it is unique and comprehensive but has rarely been evaluated with modern data. According to this theory, the region shows distinct features, which "eliminate or even reverse" planetary, that is, global, circulation dynamics. The most interesting theory in that study is a process explaining a self-amplifying mechanism of precipitation events, possibly supporting the buildup of El Niño-conditions.

The existence of a low-level jet off the west coast of South America at about the $950 \mathrm{hPa}$ level has been stated for regions further south from northern Chile to central Peru (Garreaud and Muñoz [15], Toniazzo et al. [2], and Rahn and Garreaud [16]). Using remote sensing and model data, they found diurnal and quasi-weekly cycles, in accordance with the theory of Lettau [13]. Takahashi [7] analysed simulated wind fields during strong El Niño-events and found several components of the conceptual model of Lettau [13], like the breakdown of the coastal low-level jet (CLLJ) during rainy phases and a diversion of the low-level wind field to a more westerly flow. Another model experiment was used by the same author (Takahashi [1]), to isolate the influence of land surface heating and atmospheric water vapour. His work supports the influence of a thermotidal forcing on the diurnal cycle. Toniazzo et al. [2] employed modelling efforts, to unveil dynamics of the surface layer above the southeastern Pacific. Their work also briefly addresses the conditions in North Peru, stating the presence of a strong inversion layer at about $1800 \mathrm{~m}$ and dynamical diurnal tidal waves, caused by the daytime heating of the western slopes of the Andes Cordillera. This heating produces gravity-wave pulses which travel westwards at about $25 \mathrm{~ms}^{-1}$. Our study investigates those findings as far as they are detectable in surface meteorological conditions.

\section{Material and Methods}

The district of Piura forms part of the transition zone from the humid coastal plains to the north in Ecuador and the strongly arid conditions in the Sechura Desert. Perpendicular to this transition, there is a longitudinal humidity gradient between the hyperarid coast and the foot zone of the Andes mountain chain (Münchow et al. $[17,18]$ ). While the coastal town of Paita receives only about $15 \mathrm{~mm}$ of annual precipitation, the value increases to about $700 \mathrm{~mm}$ in Morropon. The mountain valleys of Huancabamba and San Ignacio have similar annual totals of 715 and $900 \mathrm{~mm}$, respectively.

The region is covered by sufficient climate observations to reflect the spatial heterogeneity. There are ten climate stations operated by the Peruvian weather service (Servicio Nacional de Meteorología e Hidrología (SENAMHI)). But the data quality is questionable: the instrumentation is not state-of-the-art and data storage and accessibility is limited. Nevertheless, temperature and pressure data from Talara $\left(04^{\circ} 34^{\prime} 34^{\prime \prime} \mathrm{S} / 81^{\circ} 15^{\prime} 20^{\prime \prime} \mathrm{W}\right)$ and Piura $\left(05^{\circ} 10^{\prime} 11 \mathrm{~S} / 80^{\circ} 37^{\prime} 38 \mathrm{~W}\right)$ dating back to 1957 could be analysed for long-term trends.

The Project SECCO (Sechura ECosystem Monitoring and Climate Observation) was initiated on basis of long-term vegetation monitoring (Richter and Ise [19]) which started in 1998 in the vicinity of the port town of Paita. SECCO was implemented in 2010 to complement the previous work with climate monitoring and analyses. In 2011 the Universidad de Piura supplied the project with eight more climate stations with sophisticated sensor equipment and a high temporal resolution (10 $\mathrm{min}$ ) (Table 1 ).

The stations cover a climatic gradient from the coast to the eastern escarpment of the Andes (Figure 1). The high temporal resolution enables a detailed analysis of single events, although the time series of the whole gradient cover just three years. The station in Piura has data coverage since 1995, but during this time several sensors were replaced with more modern devices (wind, radiation, and relative humidity). All the time series have been quality checked and homogenized, to detect deteriorating data quality and to eliminate implausible breaks. This is done by checking for fixed and cyclic limits (diurnal cycle of temperature and radiation), temporal change gradients (temperature, relative humidity, and radiation), and relations between correlated variables (precipitation and temperature, temperature and relative humidity, and temperature and wind speed). Furthermore, recommendations given by the WMO are applied (Plummer et al. [20]). 
TABLE 1: Climate stations and equipment.

\begin{tabular}{|c|c|c|c|c|c|}
\hline Station type & Sites (dist. from coast) & Latitude & Longitude & Elevation ( $\mathrm{m}$ asl) & Sensors \\
\hline \multirow{8}{*}{ NRG } & Negritos $(0 \mathrm{~km})$ & $04^{\circ} 39^{\prime} 30 \mathrm{~S}$ & $081^{\circ} 18^{\prime} 14 \mathrm{~W}$ & 25 & Air temperature \\
\hline & Bayovar $(0 \mathrm{~km})$ & $05^{\circ} 47^{\prime} 55 \mathrm{~S}$ & $081^{\circ} 03^{\prime} 57 \mathrm{~W}$ & 150 & Relative humidity \\
\hline & Piura (74 km) & $05^{\circ} 10^{\prime} 13 \mathrm{~S}$ & $080^{\circ} 38^{\prime} 18 \mathrm{~W}$ & 42 & Precipitation \\
\hline & Morropon (148 km) & $05^{\circ} 11^{\prime} 22 \mathrm{~S}$ & $079^{\circ} 58^{\prime} 01 \mathrm{~W}$ & 131 & Wind speed \\
\hline & Huancabamba (205 km) & $05^{\circ} 14^{\prime} 54 \mathrm{~S}^{\prime}$ & $079^{\circ} 27^{\prime} 15 \mathrm{~W}$ & 2005 & Wind gusts \\
\hline & San Ignacio $(257 \mathrm{~km})$ & $05^{\circ} 09^{\prime} 00 \mathrm{~S}$ & $078^{\circ} 59^{\prime} 04 \mathrm{~W}$ & 1252 & Wind direction \\
\hline & & & & & Global radiation \\
\hline & & & & & Barometric pressure \\
\hline \multirow{14}{*}{ Campbell } & \multirow{14}{*}{$\begin{array}{l}\text { Cangrejos }(1 \mathrm{~km}) / \text { Colan } \\
(1 \mathrm{~km}), \text { (relocated in } 2013 \\
\text { due to safety issues) }\end{array}$} & $05^{\circ} 09^{\prime} 27 \mathrm{~S}$ & $081^{\circ} 09^{\prime} 53 \mathrm{~W}$ & 62 & Air temperature $(2 \mathrm{~m})$ \\
\hline & & $05^{\circ} 00^{\prime} 26 \mathrm{~S}$ & $081^{\circ} 03^{\prime} 22 \mathrm{~W}$ & 11 & Air temperature $(0.5 \mathrm{~m})$ \\
\hline & & & & & Relative humidity (2 m) \\
\hline & & & & & Relative humidity $(0.5 \mathrm{~m})$ \\
\hline & & & & & Precipitation \\
\hline & & & & & Wind speed \\
\hline & & & & & Wind gusts \\
\hline & & & & & Wind direction \\
\hline & & & & & $\begin{array}{l}\text { Radiation balance } \\
\text { (shortwave and infrared) }\end{array}$ \\
\hline & & & & & Barometric pressure \\
\hline & & & & & Soil temperature (3 levels) \\
\hline & & & & & Soil heat flux \\
\hline & & & & & Soil moisture (3 levels) \\
\hline & & & & & Ground water level (3 wells) \\
\hline \multirow{7}{*}{ Hobo } & \multirow{7}{*}{$\begin{array}{l}\text { Cangrejos }(0.5 \mathrm{~km}) / \\
\text { Colan }(0.5 \mathrm{~km}) \\
\text { (relocated in } 2013 \text { due to } \\
\text { safety issues) } \\
\text { Tavara }(110 \mathrm{~km})\end{array}$} & $05^{\circ} 09^{\prime} 01 \mathrm{~S}$ & $081^{\circ} 10^{\prime} 08 \mathrm{~W}$ & 6 & Air temperature $(2 \mathrm{~m})$ \\
\hline & & $05^{\circ} 03^{\prime} 15 \mathrm{~S}$ & $081^{\circ} 03^{\prime} 43 \mathrm{~W}$ & 73 & Relative humidity ( $2 \mathrm{~m}$ ) \\
\hline & & & & & Wind speed \\
\hline & & & & & Wind gusts \\
\hline & & & & & Wind direction \\
\hline & & $05^{\circ} 08^{\prime} 11 \mathrm{~S}$ & $080^{\circ} 18^{\prime} 18 \mathrm{~W}$ & 178 & Precipitation \\
\hline & & & & & Global radiation \\
\hline
\end{tabular}

To unveil typical patterns of the diurnal and annual cycle along the climatic gradient from the coast to the mountains, average daily zonal gradients of potential temperature, specific humidity, and sea level pressure were calculated for the coastal plain and the whole transect including the mountain stations. This was done by linear regression of the hourly values of each climate variable against the distance along the transect. Hovmoller plots of those climate variables were generated by means of the Golden Software Surfer Program, using the inverse distance to a power algorithm. This algorithm is capable of honouring the observed data and does not produce areas, where values are extrapolated beyond a plausible range.

Long-term trends and oscillations were derived from the time series by low-pass filtering and fast Fourier transformation (Brooks [21]). The resulting waves were then fitted to the observed data and offset, amplitude, and phase were derived by minimizing the variance of the residuals.
The fitted function has the following parameters:

$$
X=\frac{X_{a}}{2} \cdot \sin \left(\frac{t+\Delta_{t}}{\lambda \cdot 2 \pi}\right)+X_{\mathrm{avg}},
$$

where $X$ denotes the predicted value, $X_{a}$ is the amplitude of the respective cycle, $t$ is the time step, $\lambda$ is the wave length, and $\Delta_{t}$ is the phase shift from the beginning of the period and represents the start of the climatological cycle. Superposition of waves with different parameters is used to calculate anomaly time series. The residuals are submitted to low-pass filtering, to unveil noncyclic patterns and trends.

High-resolution data from the new stations (Table 1) served to recognize variations and characteristics of the annual and diurnal cycles, regarding all available climate variables. For this, all datasets have been integrated into a common database, enabling us to compute cycles of average and extreme values for different time periods and seasons.

To recognize the zonal patterns and gradients during the year, the annual cycle of the three important descriptive 


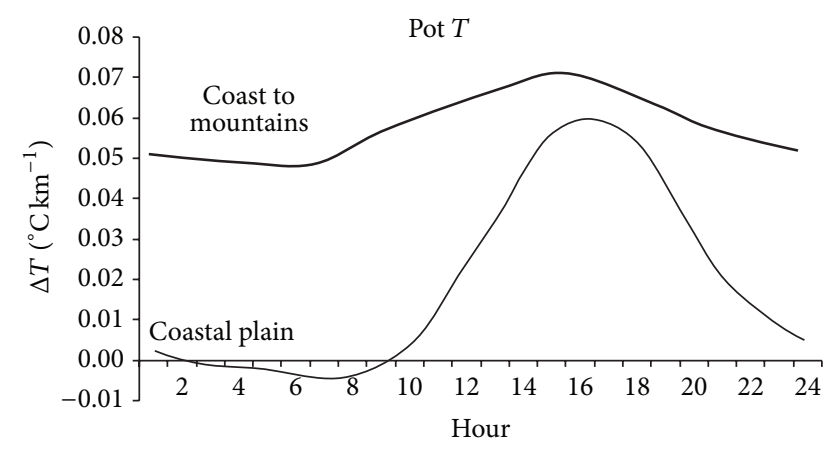

(a)

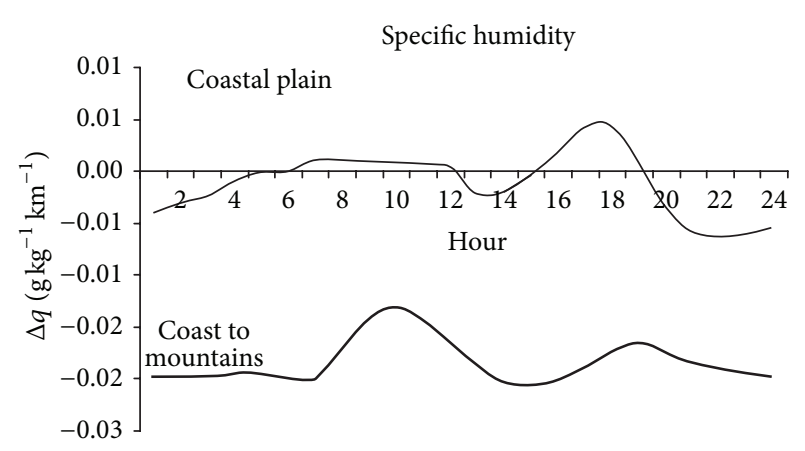

(b)

FIGURE 2: Daily cycle of gradients of potential temperature (a) and specific humidity (b) for stations in the coastal plain only (thin line) and the whole transect (thick line).

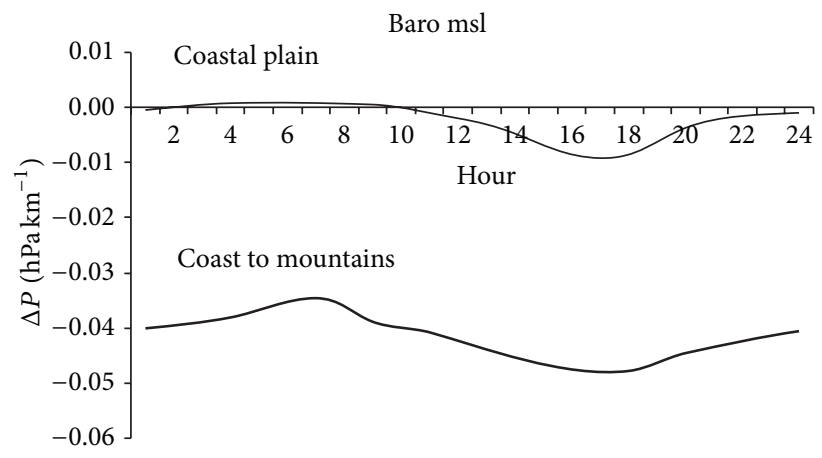

(a)

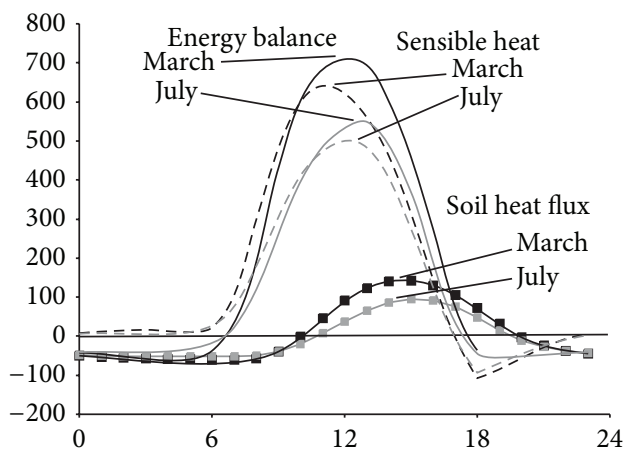

(b)

FIgURE 3: Daily cycle of gradients of sea level pressure (a) and the energy balance (b) at the coastal station Cangrejos.

climate variables, potential temperature, specific humidity, and the surface level winds, was depicted along the gradient of the nine stations, from the coast to the eastern escarpment of the Andes in form of isopleths. By this, variations of climate gradients during different times of the year and day were recognized and underlying processes identified. The statistical significance of the annual cycles could be confirmed by comparison to the long-term data available for Piura and Talara (Section 3.3).

The sophisticated Campbell station at the coast served to calculate radiation and energy balance, applying a modified combination approach of the Penman-Monteith equation (Szarzynski [22], Rollenbeck [23], and Rollenbeck and Anhuf [24]). This shall shed some light on the influence of the sea breeze on energy exchange within the coastal boundary layer and the role of energy absorption by atmospheric water vapour and the land surface.

\section{Results}

3.1. Daily Cycles. The average daily cycle was calculated for two spatial domains, similar to the exclusion model runs of Toniazzo et al. [2]: the coastal plain alone and the whole transect from the coast to the eastern escarpment of the Andes (cf. Figure 1).
Potential temperature (Figure 2(a)) shows a strong daily cycle in the coastal plain, where temperature differences up to $5^{\circ}$ per $100 \mathrm{~km}$ at noon could be observed. During the night the gradient becomes slightly negative. By including the mountain stations, the gradient is constantly positive, but the daily variation is less pronounced. Obviously, the daily thermal oscillations generally happen in the coastal plain, while the mountains only show minor variations. Specific humidity (Figure 2(b)) seems to be quite uniform in the coastal plain, with little daily variability.

The zonal pressure gradient (Figure 3(a)) is weak in the coastal plain, but notable when considering the whole transect. It varies slightly during the day, with the lowest value in the afternoon. The components of energy balance at the coastal station Cangrejos (Figure 3(b)) are dominated by sensible heat, which makes up about $56 \%$ of the total in March and still $50 \%$ in July. Latent heat flux is almost completely absent.

The wind field (Figure 4) shows the typical cycle of the sea breeze at the coast but some $120 \mathrm{~km}$ inland the divergence modifies this cycle, causing westerly stream flow throughout the day. This flow increases around noon and is strongest in the afternoon, contributing to convergent flows with a peak around 14:00 local time above the mountains. 


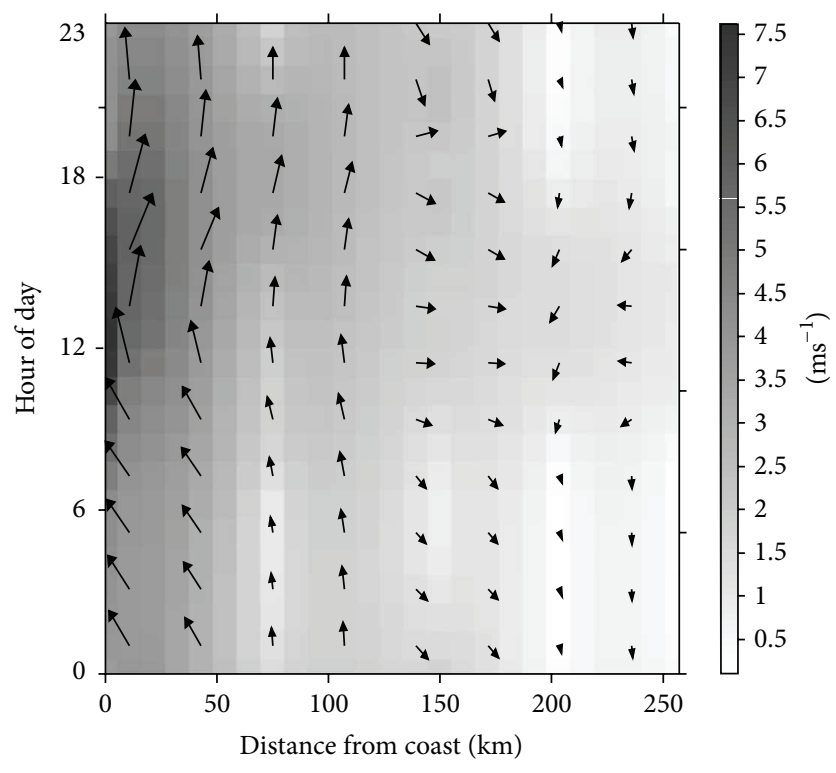

FIGURE 4: Daily cycle of the wind field along the transect from the coast to the mountains.

3.2. Annual Cycles. Temperature in Cangrejos and Piura indicates a regular annual cycle, which can be closely fitted with a sine wave with a phase length of one year and an amplitude of $7^{\circ} \mathrm{C}$ in Cangrejos and $9^{\circ} \mathrm{C}$ in Piura (Figure 5). The lower amplitude of $4^{\circ} \mathrm{C}$ at Morropon is probably caused by the influence of denser cloudiness and higher precipitation. Solar radiation and sea level pressure decrease from the coast towards the mountains. The energy balance has its peak value in March because more energy is used for reevaporation of the precipitation. The albedo in Cangrejos (not shown) remains very constant throughout the year at around 0.18.

The distance-time diagrams depict the annual cycle along the transect (Figure 5). The potential temperature shows the strong influence of the mountains ("Massenerhebungseffekt" = influence of elevated land masses), where variation throughout the year is smallest. The coastal plain has a more distinguished cycle, with the highest temperatures occurring in February in the centre of the plain around Chulucanas/ Morropon.

Specific humidity has a distinct pattern during the annual course: As expected, it is lowest in the Andes, due to the lower air density. The annual cycle is completely decoupled from the low lands east and west: there, the driest air is registered in hemispheric summer; the rainy season with the highest specific humidity values occurs in June. The rest of the year is characterised by drier conditions, especially directly at the coast and in the western foot zone of the Andes. The surface level winds are in line with these observations. In the coastal plain a strong southern wind blows throughout the year, reaching peak velocities of 12 to $16 \mathrm{~ms}^{-1}$ in the afternoon. Besides the permanent divergence due to horizontal wind shear, slight deviations to easterly components can be observed in August. The western foot zone of the Andes is dominated by slightly weaker northerly and northwesterly winds. The easterly components crossing the Andes are decoupled from the flow patterns in the surface layer of the coastal plain.

The short observation period of the Niño-5-Network does not supply statistically robust data to allow the derivation of spatial rain fall patterns. The first two years 2010 (total of $1.5 \mathrm{~mm}$ ) and 2011 (total of $3.5 \mathrm{~mm}$ ) were characterized by a continuing drought at the coast with only a few detectable precipitation events, apparently in conjunction with the prevailing La Niña-conditions in the tropical pacific. Nevertheless, the expected gradient (Figure 2) is still visible, with very dry conditions directly at the coast and an increase towards more rainy conditions at the foot zone of the Andes. Hence, the rainfall distribution does not follow the atmospheric moisture patterns but is much more controlled by thermal and dynamic processes. The annual cycle is quite similar at these lowland stations, with a peak in February and a rather small secondary peak in December.

3.3. Long-Term Patterns and Trends. Besides episodic disturbances, the climate in the northwest of Peru follows a rather constant cycle. Most of the climate variables can be fitted with a combination of sine waves with a phase length of one year and a second weaker cycle with a duration of half a year (Figure 7). The parameters of the sine wave, that is, amplitude, offset, and phase, are given in Table 2.

The long-term patterns are dominated by the influence of ENSO. Temperature and relative humidity increase during rainy episodes, while wind speed and radiation are lower. This is reflected in the long time series from the WMO station Piura-Miraflores (Figure 8), where El Niño-events are recognized by distinct temperature peaks. The heavily smoothed ten-year low-pass filter shows no significant trend towards warming, but rather there seems to be slow oscillations with a phase length of about 25 years.

\section{Discussion}

The sharp gradient from humid conditions in Ecuador to the arid regime of the Sechura Desert is caused and maintained by the interaction of global and regional processes (Horel and Cornejo-Garrido [25]). Cyclic variations of the different climate elements and their gradients reflect those processes.

The thermal low situated above the Andes (Figure 6) plays a key role in the diurnal cycles of the gradient of potential temperature. The gradient from coast to mountains is permanent, while strong thermal variations are present in the plain. In contrast, the pressure gradients in the coastal plain are weak; hence, the major driver for wind is the combined influence of the sea breeze and the anabatic winds at the western escarpment of the Andes, the extended sea breeze (Takahashi [1]). The diurnal cycle of the wind field (Figure 4), together with the observed air pressure and temperature gradients, indicates the thermal forcing of the wind field: In the morning hours, the coastal jet experiences a deviation offshore, while in the afternoon, onshore components appear. Diverging patterns are seen at $50 \mathrm{~km}$ and again at $120 \mathrm{~km}$ inland in the morning, but in the afternoon, these structures increase in strength and shift further to the east. Apparently, this dynamic oscillation suppresses deep convection above 

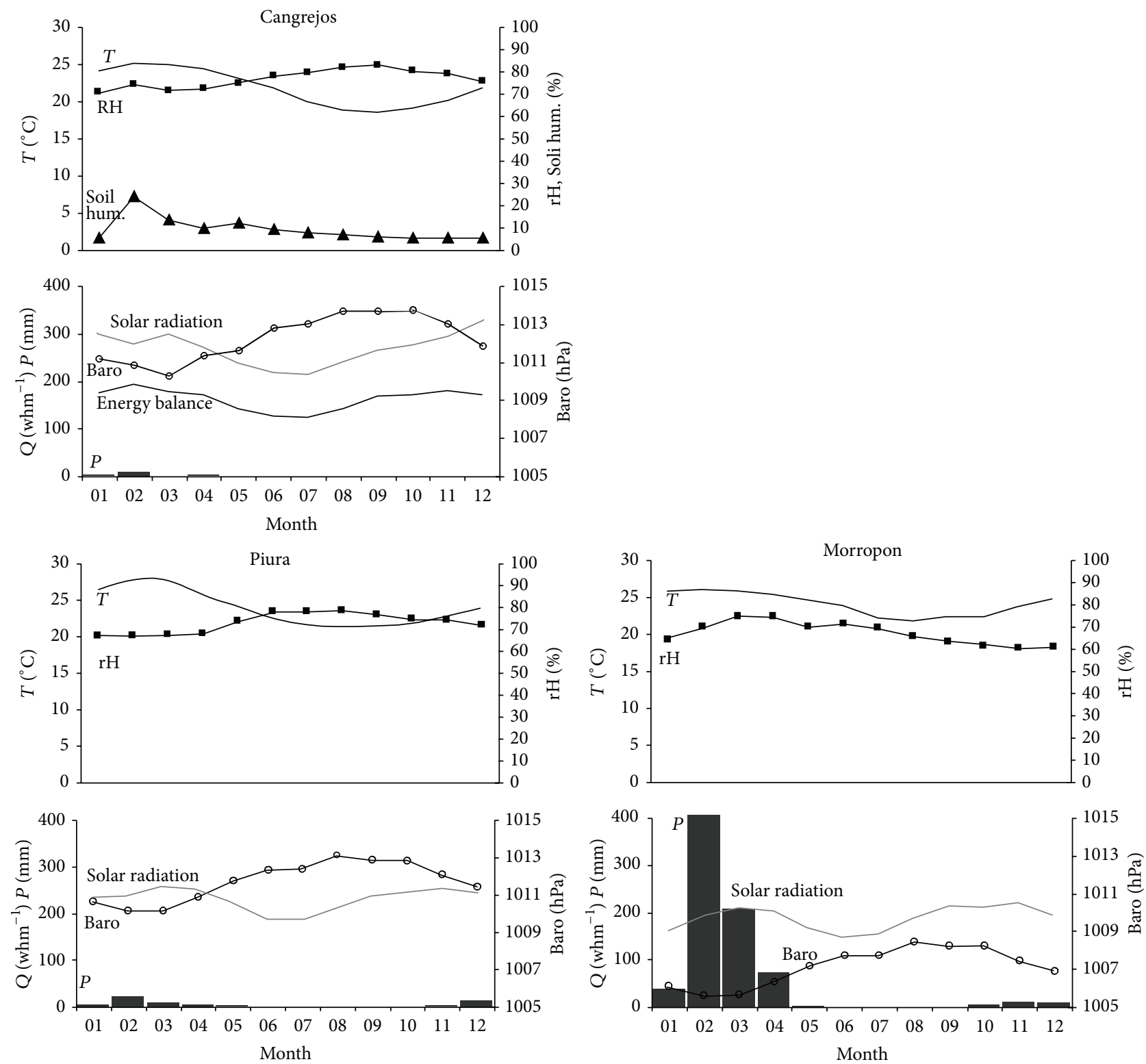

Figure 5: Annual cycles of temperature $(T)$, relative humidity $(\mathrm{rH})$, solar radiation, sea level pressure (Baro), and precipitation $(P)$ for three stations along the transect (including measurements of soil moisture and the energy balance at Cangrejos).

the coastal plain, which would normally appear, given the high temperatures and sufficient atmospheric moisture. Toniazzo et al. [2] found similar cycles further to the southeast, driven by the daytime heating of the western slopes of the Andes Cordillera. They attribute this oscillation to semidiurnal propagating waves at the $800 \mathrm{hPa}$ level above the ocean. Given the fact that the driver for this oscillation is the land surface, these waves are probably even stronger in the coastal plain than above the ocean.

The annual variations are similar in waveform and amplitude like the daily cycle. During the short rainy season in February and March, the divergence above the coastal plain breaks down and, together with the higher temperatures and associated higher atmospheric moisture, the subsidence may be sometimes superseded and convection may reach the point of rainfall formation. The rest of the year is characterised by the permanent divergent surface level winds and the strong coastal jet. The easterly wind components observed in the Andes are driven by the tropical easterlies and well above the inversion layer.

The main drivers behind the rather regular climate oscillation are (i) the annual cycle of SST (Bazo et al. [10]). This obviously affects air temperature, relative humidity, barometric pressure, and even radiation, which is largely controlled by atmospheric water vapour, only partially in form of cloudiness. The shorter half year cycle seems to be associated with the (ii) displacement of the ITCZ, which traverses the region two times a year. The existence of shorter 


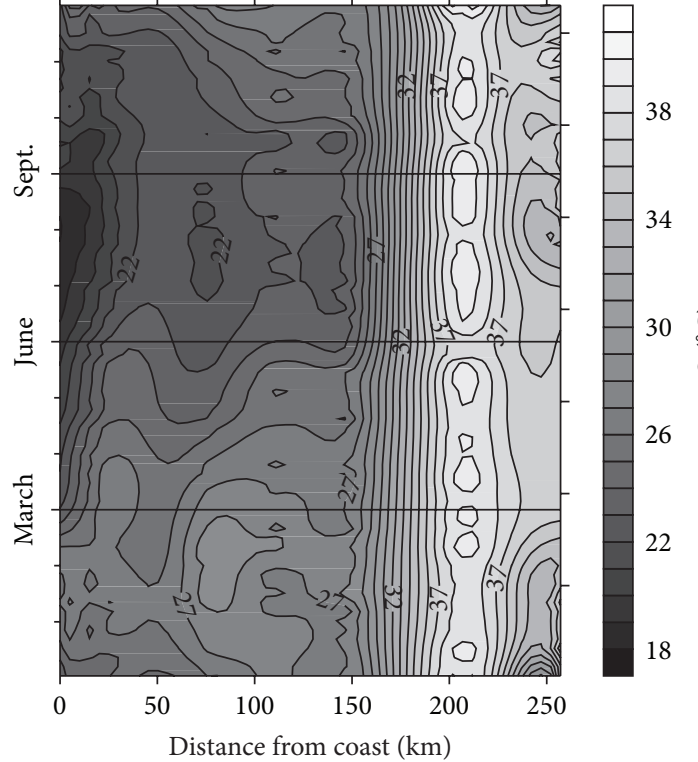

(a)

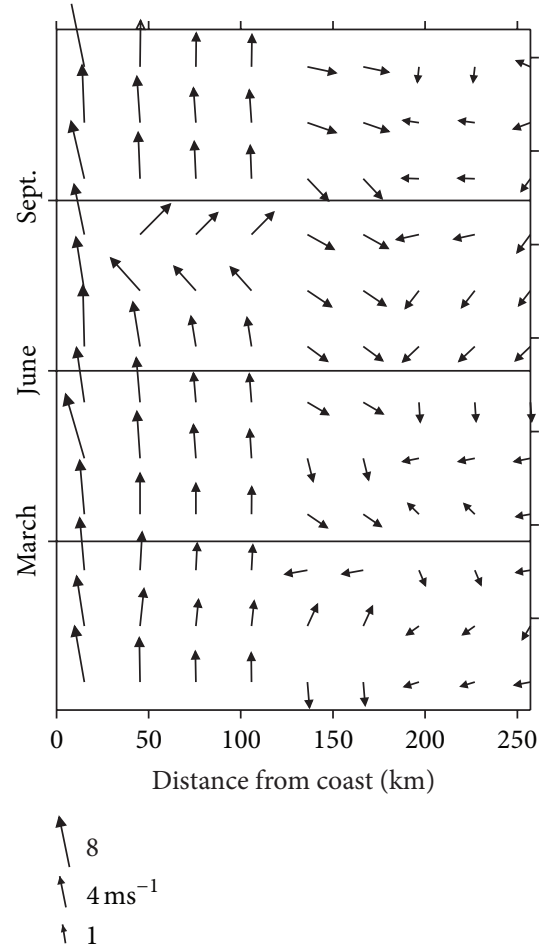

(c)

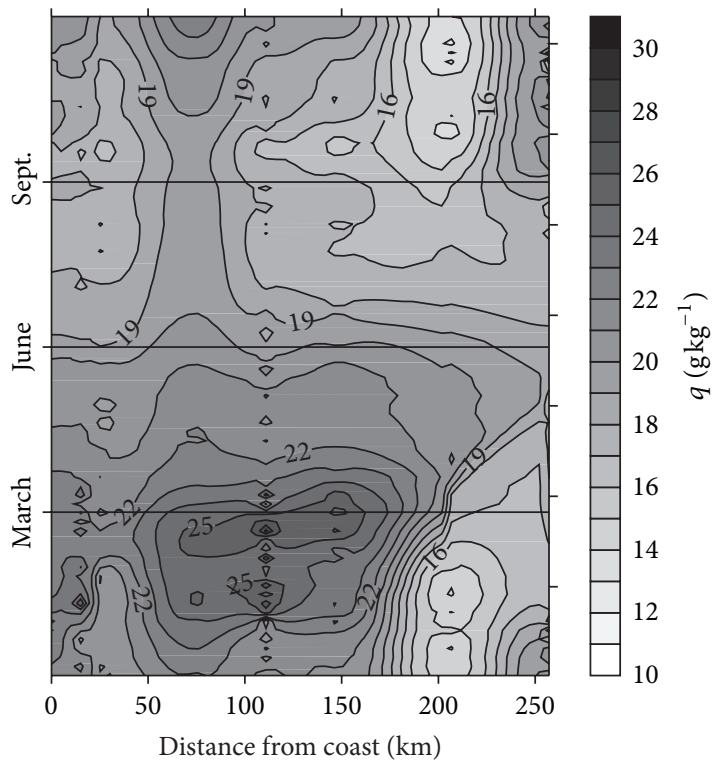

(b)

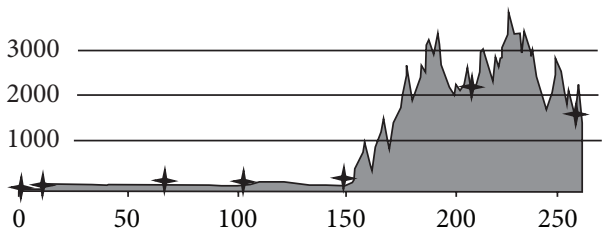

FIGURE 6: Distance-time diagrams for the annual cycle of (a) potential temperature, (b) specific humidity, and (c) the wind field along the transect. (d) Altitudinal profile of the transect and location of the climate stations (stars).

cycles like the (iii) thermotidal surge proposed by several authors (Takahashi [1], Rahn and Garreaud [16], and Lettau [13]) or the Madden-Julian oscillation (Rutllant and Ulriksen [26]) coincides with our observations, but the signal is blurred by episodic disturbances, which disrupt the normal oscillation mode. Deeper knowledge may arise from the ongoing measurements in the future.
By integrating the observations of this study with findings of other investigations, a conceptual model of the regional circulation and its variations can be constructed.

Along the coast, relatively high wind speeds are observed, supporting the theory of a low-level jet stream, the CLLJ. It is confined by the strong inversion layer from above, and the subsiding air flows further inland. This subsidence causes 


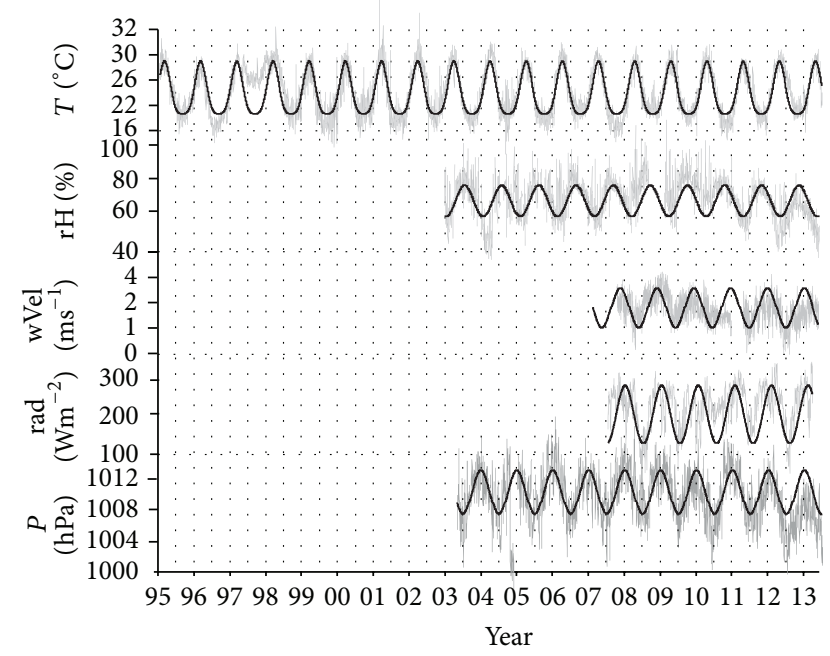

Figure 7: Average daily air temperature, relative humidity, wind velocity, solar radiation, and barometric pressure in Piura and fitted sine waves (above).

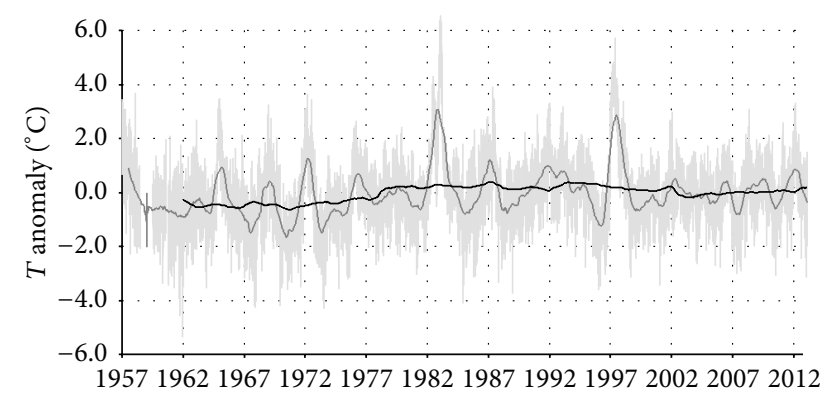

FIgURE 8: Long-term anomalies of temperature in Piura. Daily average (grey), 1-year smoothed curve (dark grey), and 10-year smoothed curve (black).

the CLLJ to develop divergent branches, which divert from southern to western and northwestern directions, leading to the mentioned "desert wind" (Lettau [13]) or extended sea breeze (Takahashi [1]). The air mass, initially cooled above the coastal waters, will increase evaporation, when warming up above the terrestrial parts of the coastal region. The desert wind forms a counter flow with northwesterly directions in the proximity of the western escarpment of the Andes. Anabatic forcing during the day draws in the heated air masses and integrates them into the convective patterns above the mountains. Here, the inversion layer is superseded, due to the higher potential temperature in the surface layer, and moist convection sets in. At higher atmospheric levels, these air masses are then entrained into the tropical easterlies. There they carry relatively warm air (potential temperature $\sim 37^{\circ} \mathrm{C}$ ) to the west, further intensifying the inversion layer above the coastal plain.

On the western side of the CLLJ, above the coastal waters, stream flow patterns oscillate quite regularly during the day: At night, offshore winds transport energy stored mainly in the soil to the cold ocean. The soil heat flux starts to become negative about two hours after sunset. At sunset, sensible heat flux is negative too, but around midnight it becomes positive again at the coast. Probably, warmer air from further inland transfers energy to the land surface directly at the coast. In the morning hours, wind calms down, before the sea breeze sets in at noon. At this time of the day, episodically low thin clouds can be seen above the coast, a hint for the formation of shallow convection. Later during the day, the condensation level rises above the inversion layer and the clouds decay. This dry convection may be the mechanism which drives the "helical vortex" proposed by Lettau [13]. A crucial component of the concept is the Ekman drift, which diverts the upper branch of the helical vortex to offshore directions. When crossing the equator northwards, the Coriolis parameter changes signs and the offshore component ceases. In line with that hypothesis, Carillo and Bazo [27] have pointed out the role of the vertical vorticity profile in the formation of instability and consequently precipitation. Besides increased sea surface temperatures and convergent flows caused by the sea breeze, this might be the required additional factor for breaking up the stable inversion layer.

Precipitation events show some contradictory behaviour: While Takahashi [7] identifies an intensification of onshore components of the boundary layer wind field as main driver for deep convection and precipitation our observations show a different behaviour. During rain events, the regular southern winds in the coastal plain are interrupted and easterly components set in. The weakening of the divergence observed during the short rainy season may suffice to break up the subsidence and the associated inversion layer and allow local moist convection to occur. However, it is also possible that there are two different mechanisms of rainfall formation: one that occurs with average SST and a normal ocean circulation and another associated with warm coastal waters and reversal of ocean currents. Carillo and Bazo [27] have shown examples of such non-ENSO rainfall extremes for the year 2002. In their modelling analysis, vorticity is transferred by ascending air masses to higher levels, where it counteracts the tropical easterlies and by this weakens the inversion.

According to Lettau [14], changes in the radiation balance associated with the onset of precipitation may diminish the thermal forcing of the CLLJ. The drift current for heat export to the ocean is reduced, upwelling becomes weaker, and more moist convection occurs to dispose of the net radiation. This gives a further feedback for more moist convection and can finally emerge into a longer phase of convective precipitation, that is, the typical local El Niño. This kind of El Niño should not be confused with the ENSO-phenomenon and has closely been observed in 2008, while ENSO-conditions remained in a cold phase (Bendix et al. [11], Tedeschi et al. [28]). Rutllant [29] attributes those changes to a south shift of the ITCZ and also states the positive feedback of the changes in radiation balance and wind field for longer periods of rain in this otherwise rather dry environment. Pineda et al. [30] found the influence of such circulation changes to increase the rainfall in the coastal mountains of South Ecuador and North Peru. In the wide coastal plain of the Sechura the changes are less pronounced, as could be observed during the 2008 rain period (Bendix et al. [11]) and also in our data records. 
TABLE 2: Parameters of the fitted sinus function.

\begin{tabular}{lccc}
\hline & Amplitude & Offset & Phase \\
\hline Temperature & $6.3 \mathrm{~K}$ & $23.8^{\circ} \mathrm{C}$ & 1 September \\
Relative humidity & $12 \%$ & $70 \%$ & 18 August \\
Wind velocity & $1.4 \mathrm{~ms}^{-1}$ & $2.3 \mathrm{~ms}^{-1}$ & $1 \mathrm{March}$ \\
Solar radiation & $100 \mathrm{Wm}^{-2}$ & $220 \mathrm{Wm}^{-2}$ & 1 January \\
Barometric pressure & $3.2 \mathrm{hPa}$ & $1007.5 \mathrm{hPa}$ & $1 \mathrm{March}$ \\
\hline
\end{tabular}

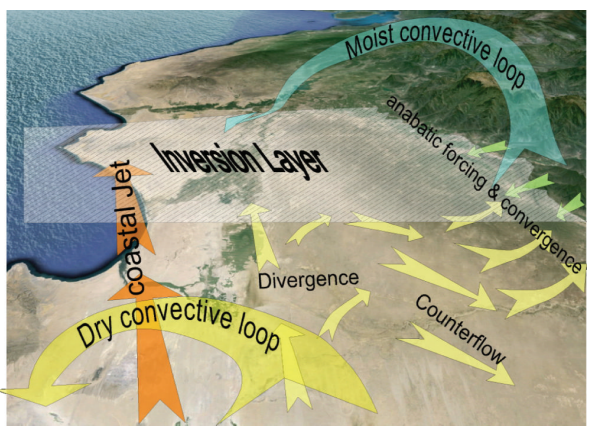

Figure 9: Conceptual model of flow patterns in the region of Piura.

The stronger difference between the total radiation budget and sensible heat during the rainy season (Figure 9) is a further hint to the radiation balance as a driver for precipitation.

\section{Conclusions and Outlook}

The new climate station network installed since 2010 has proven its value to detect local and regional climate oscillations on different time scales in the Piura Region. The climate conditions show a strong self-induced stability, caused not only by the typical west coast climate, but also by regional ecoclimatological factors, like the low transfer of latent heat and divergent surface winds. In agreement with Lettau [14], the initial impulse for rainfall is considered as a potential trigger for a fundamental change of the regional circulation. Due to the constantly low SST during our observation period, this remains subject of continuing research in this region. Whether and how regional factors contribute to the buildup of El Niño-conditions can only be analysed when a strong episode occurs. Nevertheless, it is clear that local warm water episodes are not necessarily in phase with the ENSO-cycle (Bendix et al. [11], Tedeschi et al. [28]).

The main characteristics of the climatic processes are the interaction of diurnal cycles, especially that of the extended sea breeze with topographic factors and surface characteristics. The annual cycle is shaped by displacement of the ITCZ and the variations of the SST. Long-term oscillations are governed by the ENSO-cycle and on an even longer time scale a possible influence of the pacific decadal oscillation may be present.

Many of the features of the region's climate can be successfully analysed by using modelling tools and remote sensing data, but certain aspects would remain uncertain, if no detailed in situ observations would be available. In particular, small scale oscillations like the observed diurnal cycle and components of the surface energy balance can best be identified by direct measurements.

It is therefore highly desirable to continue the highresolution measurements of the Niño-5-Network and to complement the existing sensors with additional instrumentation. First of all, more data on the local energy balance would be useful to understand the variations along the gradient from coast to mountains. Currently, only one station at the coast is capable of measuring the required parameters.

An important point is the analysis of the vertical wind field. While the data from the Piura Wind Profiler (Liziola and Balsley [31]) is still under analysis, currently the boundary layer radar is inoperative (Flores et al. [32]). A rehabilitation of the system would be very useful.

An important impulse for further understanding may come from projected rain radar in the centre of the coastal plain. Cost-effective systems (Rollenbeck and Bendix [33]) have now become available, which allow a permanent monitoring of a range of 120 to $160 \mathrm{~km}$. Such data not only would be invaluable for scientific purposes, but also would improve local safety measures and early warning capabilities, if a new strong El Niño-event takes place.

\section{Conflict of Interests}

The authors declare that there is no conflict of interests regarding the publication of this paper.

\section{Acknowledgments}

The authors would like to thank the Deutsche Forschungsgemeinschaft (DFG) for generously funding this study and the Universidad de Piura for fruitful cooperation, the setup and operation of the Niño-5-Network, and the provision of long-term climate data. The authors would also like to thank Viviana Horna, Dirk Wundram, and several student assistants for supporting the field work.

\section{References}

[1] K. Takahashi, "Thermotidal and land-heating forcing of the diurnal cycle of oceanic surface winds in the eastern tropical Pacific," Geophysical Research Letters, vol. 39, no. 4, 2012.

[2] T. Toniazzo, F. Sun, C. R. Mechoso, and A. Hall, "A regional modeling study of the diurnal cycle in the lower troposphere in the south-eastern tropical Pacific," Climate Dynamics, vol. 41, no. 7-8, pp. 1899-1922, 2013. 
[3] C. Caviedes and W. Endlicher, "Die Niederschlagsverhältnisse in Nordperu während des El Niño-Southern OscillationEreignisses von 1983," Die Erde, vol. 120, pp. 81-97, 1989.

[4] J. Bendix, "A comparative analysis of the major El Niño events in Ecuador and Northern Peru over the last two decades," Zentralblatt für Geologie und Paläontologie, vol. 7/8, pp. 11191131, 2000.

[5] J. Bendix, "Precipitation dynamics in Ecuador and northern Peru during the 1991/92 El Niño: a remote sensing perspective," International Journal of Remote Sensing, vol. 21, no. 3, pp. 533$548,2000$.

[6] G. Chen, "Variability of the Pacific wind system during the 199798 El Niño observed by TOPEX altimetry," in Proceedings of the 2nd Asian Conference on Remote Sensing, Singapore, November 2001.

[7] K. Takahashi, "The atmospheric circulation associated with extreme rainfall events in Piura, Peru, during the 1997-1998 and 2002 El Niño events," Annales Geophysicae, vol. 22, no. 11, pp. 3917-3926, 2004.

[8] P. Lagos, Y. Silva, E. Nickl, and K. Mosquera, "El Niño-related precipitation variability in Perú," Advances in Geosciences, vol. 14, pp. 231-237, 2008.

[9] A. M. Johnson, "The climate of Perú, Bolivia and Ecuador," in World Survey of Climatology, W. Schwerdtfeger, Ed., vol. 12, Elsevier, 1976.

[10] J. Bazo, M. de las Nieves Lorenzo, and R. P. da Rocha, "Relationship between monthly rainfall in NW peru and tropical sea surface temperature," Advances in Meteorology, vol. 2013, Article ID 152875, 9 pages, 2013.

[11] J. Bendix, K. Trachte, E. Palacios et al., "El Niño meets La Niñaanomalous rainfall patterns in the 'traditional' El Niño region of Southern Ecuador," Erdkunde, vol. 65, no. 2, pp. 151-167, 2011.

[12] H. H. Lettau, "Small to large-scale features of boundary layer structure over mountain slopes," in Proceedings of the Symposium on Mountain Meteorology, E. R. Reiter and J. L. Rasmussen, Eds., vol. 122, pp. 8-56, 1967.

[13] H. H. Lettau, "Dynamic and energetic factors which cause and limit aridity along South Americas Pacific coast," in World Survey of Climatology, W. Schwerdtfeger, Ed., vol. 12, 1976.

[14] H. H. Lettau, “The worlds driest climates," IES Report 101, IES, Madison, Wis, USA, 1978.

[15] R. D. Garreaud and R. C. Muñoz, "The low-level jet off the west coast of subtropical South America: structure and variability," Monthly Weather Review, vol. 133, no. 8, pp. 2246-2261, 2005.

[16] D. A. Rahn and R. D. Garreaud, "A synoptic climatology of the near-surface wind along the west coast of South America," International Journal of Climatology, vol. 34, no. 3, pp. 780-792, 2014.

[17] J. Münchow, H. Feilhauer, A. Bräuning et al., "Coupling ordination techniques and GAM to spatially predict vegetation assemblages along a climatic gradient in an ENSO-affected region of extremely high climate variability," Journal of Vegetation Science, vol. 24, no. 6, pp. 1154-1166, 2013.

[18] J. Münchow, H. von Wehrden, E. F. Rodríguez, R. A. Rodríguez, F. Bayer, and M. Richter, "Woody vegetation of a peruvian tropical dry forest along a climatic gradient depends more on soil than annual precipitation," Erdkunde, vol. 67, no. 3, pp. 241248, 2013.

[19] M. Richter and M. Ise, "Monitoring plant development after El Niño 1997/98 in northwestern Perú," Erdkunde, vol. 59, no. 2, pp. 136-155, 2005.
[20] N. Plummer, J. A. Lopez, and T. Allsopp, "Guidelines on climate observation networks and systems," WMO/TD 1185, World Meteorological Organization, 2003.

[21] B.-G. J. Brooks, "Earth scientist's guide to discrete-time power spectrum analysis," in Fourier Transforms-New Analytical Approaches and FTIR Strategies, N. Goran, Ed., pp. 481-492, InTech, 2011.

[22] J. Szarzynski, Energie- und Wasserhaushalt eines amazonischen Regenwalds, vol. 53, Mannheimer Geographische Arbeiten, Mannheim, Germany, 2000.

[23] R. Rollenbeck, Wasser- und Energiehaushalt eines neotropischen Tieflandregenwaldes, Mannheimer Geographische Arbeiten 55, Universität Mannheim, Mannheim, Germany, 2002.

[24] R. Rollenbeck and D. Anhuf, "Characteristics of the water and energy balance in an Amazonian lowland rainforest in Venezuela and the impact of the ENSO-cycle," Journal of Hydrology, vol. 337, no. 3-4, pp. 377-390, 2007.

[25] J. D. Horel and A. G. Cornejo-Garrido, "Convection along the coast of northern Peru during 1983: spatial and temporal variation of clouds and rainfall," Monthly Weather Review, vol. 114, no. 11, pp. 2091-2105, 1986.

[26] J. Rutllant and P. Ulriksen, "Boundary-layer dynamics of the extremely arid northern part of Chile," Boundary Layer Meteorology, vol. 17, pp. 41-55, 1980.

[27] M. Carillo and J. Bazo, "Dynamics of generation of extreme precipitation in the Northern of Peru," Gayana, vol. 68, no. 2, supl. t.I. Proc., pp. 83-90, 2004.

[28] R. G. Tedeschi, I. F. A. Cavalcanti, and A. M. Grimm, "Influences of two types of ENSO on South American precipitation," International Journal of Climatology, vol. 33, no. 6, pp. 13821400, 2013.

[29] J. Rutllant, "Aspectos de la circulación atmosferica de gran escala asociada al ciclo ENOS 1997-1999 y sus consecuencias en el regimen de precipitación en Chile central," in El Niño-La Niña 1997-2000. Sus efectos en Chile, S. Avara, J. Carrasco, J. Ruttlant, and E. Yañez, Eds., pp. 61-76, CONA, Valparaiso, Chile, 2004.

[30] L. Pineda, V. Ntegeka, and P. Willems, "Rainfall variability related to sea surface temperature anomalies in a PacificAndean basin into Ecuador and Peru," Advances in Geosciences, vol. 33, pp. 53-62, 2013.

[31] L. E. Liziola and B. B. Balsley, "Studies of quasi horizontally propagating gravity waves in the troposphere using the Piura ST wind profiler," Journal of Geophysical Research D: Atmospheres, vol. 103, no. 8, pp. 8641-8650, 1998.

[32] L. Flores, J. la Madrid, and J. L Chau, "Vientos troposféricos observados con el radar VHF en Piura-Perú: condiciones normales versus 'El Niño 1997-1998,' Revista Geofísica IPGH, vol. 57, pp. 81-110, 2002.

[33] R. Rollenbeck and J. Bendix, "Rainfall distribution in the Andes of southern Ecuador derived from blending weather radar data and meteorological field observations," Atmospheric Research, vol. 99, no. 2, pp. 277-289, 2011. 

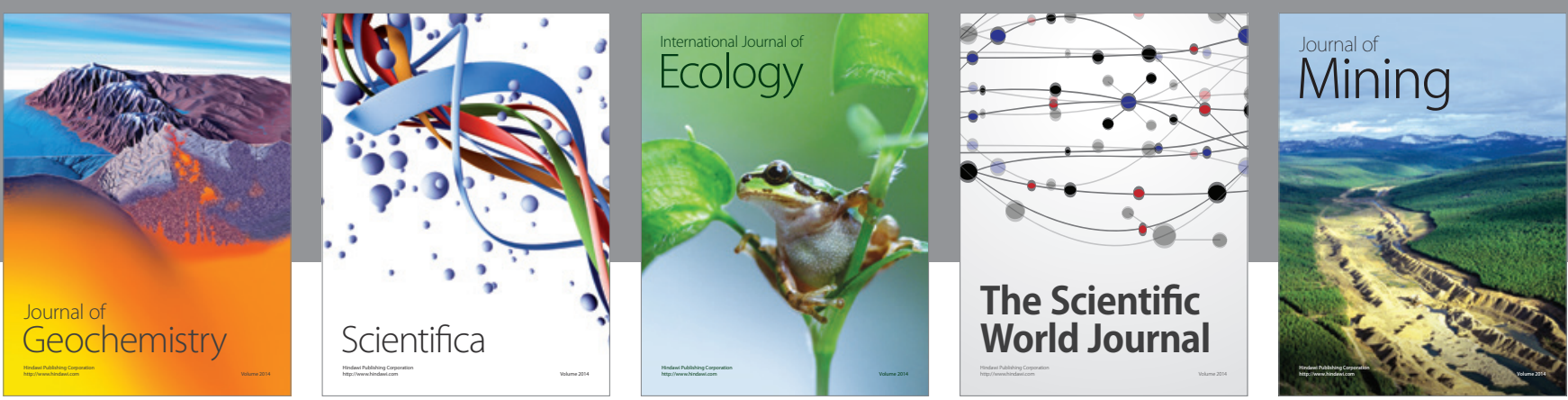

The Scientific World Journal
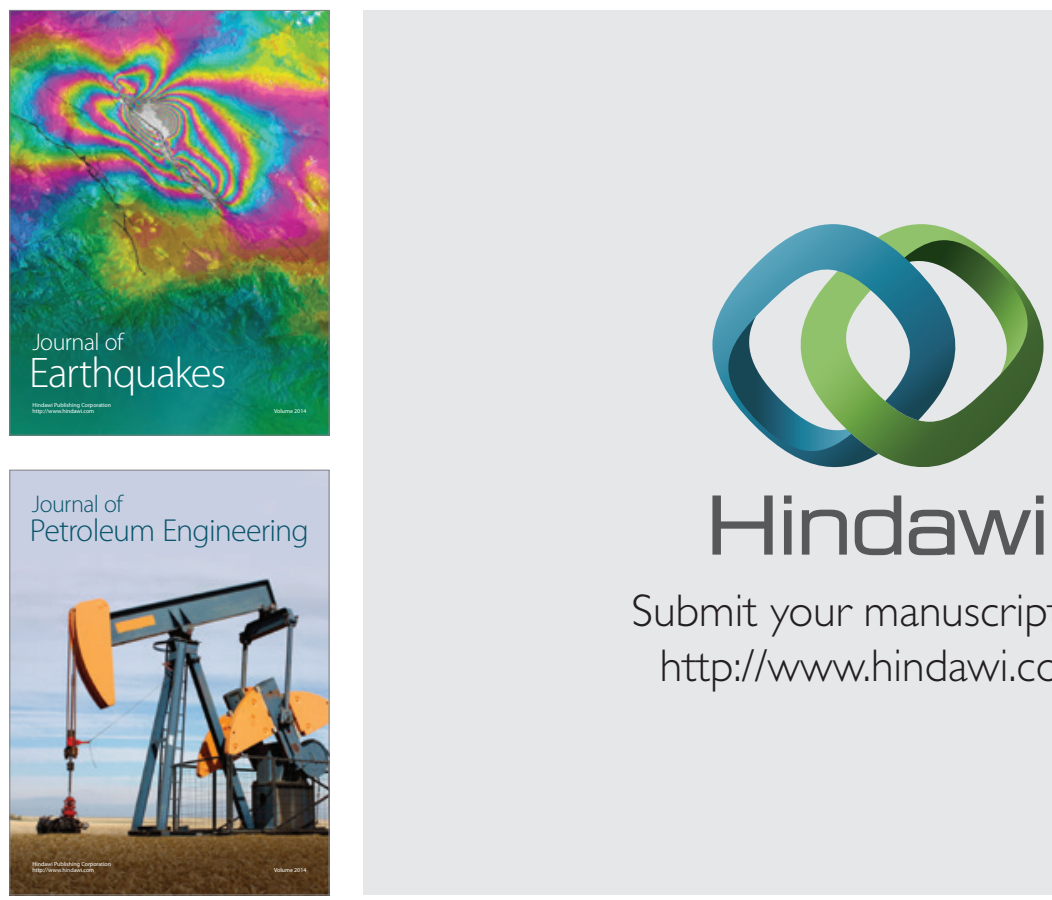

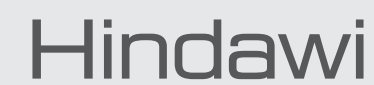

Submit your manuscripts at

http://www.hindawi.com
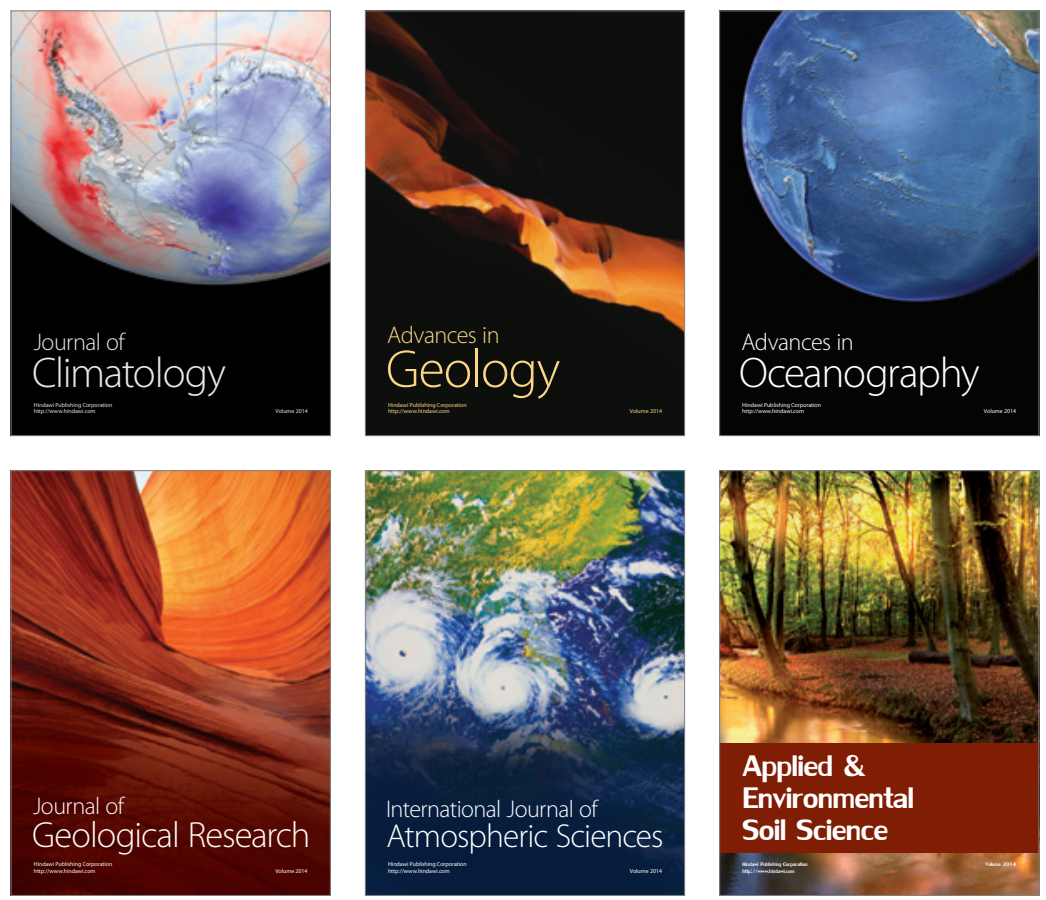
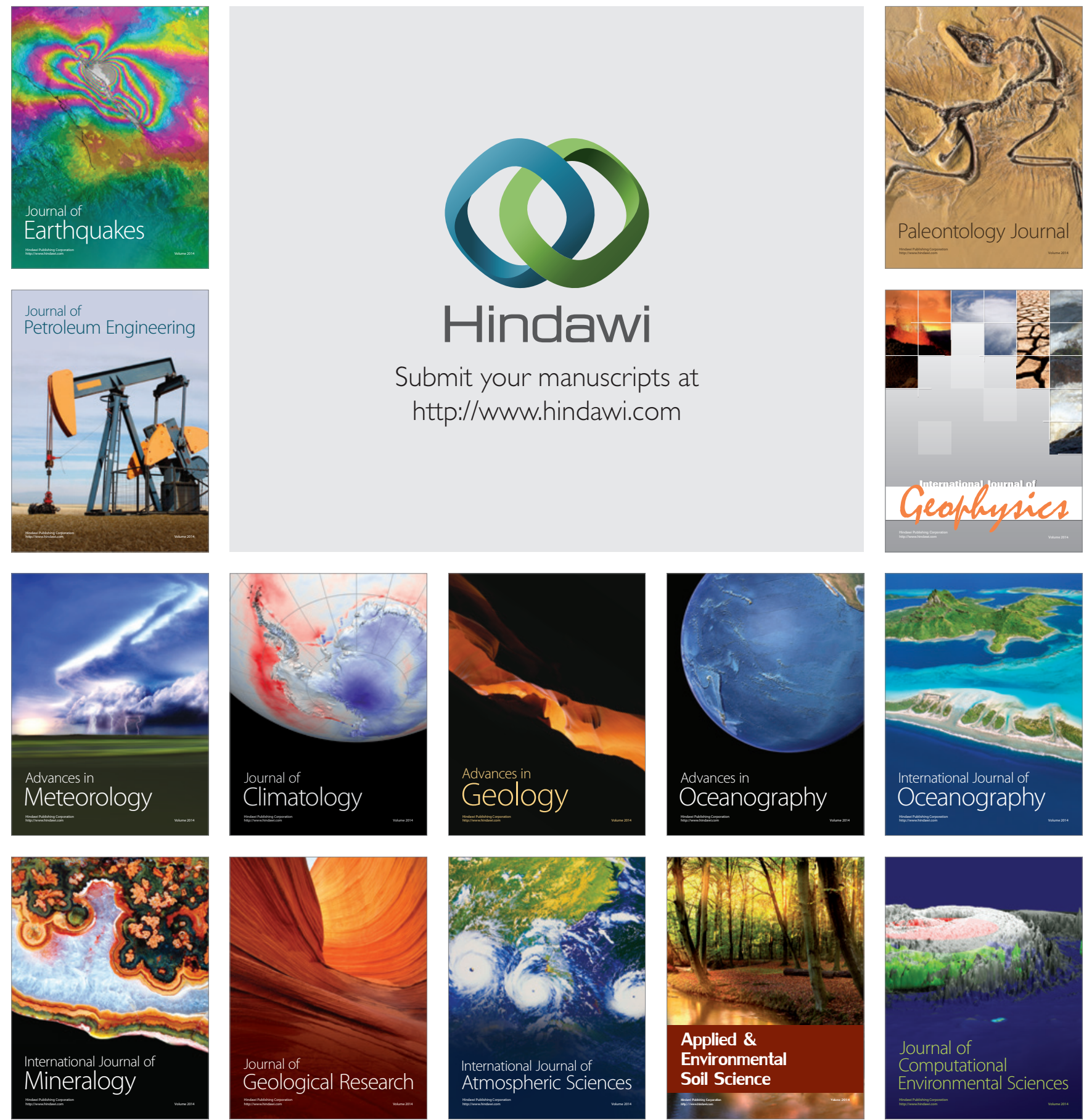